\title{
Growing Minds: Evaluating the Effect of Gardening on Quality of Life and Physical Activity Level of Older Adults
}

\author{
Aime J. Sommerfeld ${ }^{1}$, Tina M. Waliczek ${ }^{2,3,4}$, and \\ Jayne M. Zajicek ${ }^{1,3}$
}

ADDITIONAL INDEX WORDs. exercise, Life Satisfaction Inventory A, LSIA, seniors, health

Summary. A questionnaire based on the Life Satisfaction Inventory A (LSIA) was used to investigate older adult (age 50+ years) gardeners' and nongardeners' perceptions of personal life satisfaction and levels of physical activity. The LSIA measures five components of quality of life: "zest for life," "resolution and fortitude," "congruence between desired and achieved goals," "physical, psychological, and social self-concept," and "optimism." Additional multiplechoice questions were asked to determine respondents' level of physical activity, perceptions of overall health and well-being as well as to gather demographic information. The survey was posted on a university homepage for $\approx 1$ month. Responses were gathered from 298 participants who differentiated themselves as gardeners or nongardeners by responding positively or negatively to the question "do you garden?" Results indicated statistically significant differences in comparisons of overall life satisfaction scores with gardeners receiving higher mean scores indicating more positive results on the LSIA. Four individual quality-of-life statements included in the LSIA yielded statistically significantly more positive answers by gardeners when compared with nongardeners. Other questions regarding healthful practices revealed that personal reports of physical activity and perceptions of personal health were statistically significantly more positive among gardeners when compared with nongardeners.

$\mathrm{O}$ lder adults represent a growing part of the population of the United States, partially as a result of the baby boomer generation transitioning into the next stage of life (Miller and Washington, 2007). As stated in A Profile of Older Americans: 2007, one in every eight Americans is an older adult (65+ years). It is projected that this population will increase to 40 million people by 2010 with an estimated increase of $36 \%$ in the decade leading up to 2020 [U.S. Department of Health and Human Services (USDHHS), 2007]. In addition to this steadily growing population, the older population itself is getting older (USDHHS, 2007). Life expectancy of individuals has increased from 47.3 years in 1900 to 77.8 years in 2004 (Arias, 2007), which shows a dramatic increase in the population of older adults. However, research has

${ }^{1}$ Department of Horticultural Sciences, Texas A\&M University, College Station, TX 77843-2133

${ }^{2}$ Department of Agriculture, Texas State University, San Marcos, TX 78666

${ }^{3}$ Professor

${ }^{4}$ Corresponding author. E-mail: tcl0@txstate.edu. found that this population is at greater risk for disease as a result of decreased levels of exercise and poor dietary and/or lifestyle choices (Arterburn et al., 2004).

Physical activity is an important factor for healthy lifestyles and overall perceptions of life satisfaction of individuals (Andersen et al., 2001; Bertera, 2003; Rossner, 2001; Yusuf et al., 1996). However, it has been reported that $30 \%$ of adults older than age 60 years report no leisure time physical activity (Andersen et al., 2001). Moderate levels of physical activity are sufficient to produce significant barriers to coronary heart disease, stroke, and overall cardiovascular risk (Wannamethee and Sharper, 2001). In addition, higher levels of physical activity have been linked to healthier diets, including higher consumption of fruit and vegetables in adults older than age 60 years (Mummery et al., 2007; Sahyoun et al., 2005). The combination of moderate physical activity and increased consumption of fruit and vegetables has been reported to dramatically reduce an adult's risk for many chronic diseases and in turn improve health-related quality of life [Blanchard et al., 2004; Centers for Disease Control and Prevention (CDC), 2007].

Gardening is one of the most popular home-based leisure activities in the United States (Ashton-Shaeffer and Constant, 2005) and has been reported as the second most common leisure activity, after walking, of adults older than age 65 years (Yusuf et al., 1996). Adults garden for many reasons, including physical health and exercise, mental health, recreation, creativity, intellectualexpansion, friendship, produce quality and nutrition, spiritual reasons (including contact with nature), self-expression/selffulfillment, and cost and convenience (Ashton-Shaeffer and Constant, 2005; Blair et al., 1991). A study evaluating the effects of lifetime leisure gardening on women aged 67 to 75 years, who considered themselves to be in good to excellent health, reported that the women felt that gardening kept them mentally and physically active (Infantino, 2005). Specifically, women reported that gardening had a significant influence on positive lifetime traits, including successful and healthy aging, resiliency, hardiness, adaptability, creativity, selftranscendence, and a positive outlook on life (Infantino, 2005). Similar results were reported on research conducted with Master Gardeners and the effect gardening had on their quality of life (Boyer et al., 2002; Waliczek et al., 2005). Willcox and Mattson (1979) found that perceptions of quality of life of older adults at a residential facility was maintained over an 8 -week gardening activity period, whereas those not involved in gardening had decreased perceptions in quality of life over the same time period. Boyer et al. (2002) reported statistically significant improvements in perceptions of physical and social activity, self-esteem, and nutrition.

The primary focus of this study was to determine if gardening had a positive impact on perceptions of quality of life and levels of physical activity of older adults when compared with nongardeners in a study evaluating the effect of gardening on older adults (Sommerfeld et al., 2010).

\section{Materials and methods}

SAMPle POPUlation. The target population in this study was adults 
$50+$ years. The age of $50+$ years and older was chosen according to the standardized age for member acceptance in the AARP [formerly the American Association of Retired Persons (AARP, 2010)]. This age also served as a breakpoint to include the baby boomer population as well as to provide a simple differentiation for categorical groupings. The sample was recruited by way of an online survey that was posted on the front page of the Texas A\&M University Aggie Horticulture network for $\approx 1$ month in Spring 2005.

Respondents self-selected themselves for inclusion in the study by visiting the web page and choosing to answer the survey. No incentive was given for participating. The survey was not advertised in any manner other than the link on the web page. Respondents differentiated themselves as gardeners or nongardeners by responding positively or negatively to the survey question, "do you garden?" No definition of gardening was included with the survey question, "do you garden?" Therefore, respondents concluded whether the activities in which they participate were considered gardening activities.

Demographic survey. The demographic section of the instrument was modeled after a similar instrument (Waliczek et al., 2005) and included questions on age, gender, ethnicity, income level, and education level (Table 1 ). In addition to general demographic questions, three multiplechoice questions were included in this section and related to gardening, daily levels of physical activity, and overall feelings of health or life satisfaction.

QUALITY-OF-LIFE INSTRUMENTATION FOR OLDER ADULTS. Perceptions of life satisfaction of gardeners and nongardeners were measured using the Life Satisfaction Inventory A (LSIA) (Neugarten et al., 1961). This instrument measures psychological well-being of participants in multiple areas, including "zest for life," "resolution and fortitude," "congruence between desired and achieved goals," "physical, psychological, and social self-concept," and "optimism." The LSIA instrument has been shown to be a reliable and valid instrument through use in other research (Adams, 1969; Sexton and Munro, 1985,

Table 1. Demographic information for gardeners and nongardeners in the study evaluating the influence of gardening on life satisfaction and physical activity of older adults.

\begin{tabular}{|c|c|c|c|c|}
\hline & \multicolumn{4}{|c|}{ Do you garden? } \\
\hline & \multicolumn{2}{|c|}{ Yes/gardeners } & \multicolumn{2}{|c|}{ No/nongardeners } \\
\hline & $\begin{array}{c}\text { Frequency } \\
\text { (no.) }\end{array}$ & $\begin{array}{c}\text { Frequency } \\
(\%)\end{array}$ & $\begin{array}{c}\text { Frequency } \\
\text { (no.) }\end{array}$ & $\begin{array}{c}\text { Frequency } \\
(\%)\end{array}$ \\
\hline \multicolumn{5}{|l|}{ Gender } \\
\hline Male & 53 & 34 & 51 & 49.5 \\
\hline Female & 103 & 66 & 52 & 50.5 \\
\hline \multicolumn{5}{|l|}{ Ethnicity } \\
\hline Black & 2 & 1.3 & 3 & 2.9 \\
\hline Asian/Pacific Islander & 0 & 0.0 & 1 & 1.0 \\
\hline Hispanic & 0 & 0.0 & 2 & 2.0 \\
\hline Native American & 1 & 0.6 & 3 & 2.9 \\
\hline White & 153 & 96.8 & 93 & 91.2 \\
\hline Other & 2 & 1.3 & 0 & 0.0 \\
\hline \multicolumn{5}{|l|}{ Age group (years) } \\
\hline $50-59$ & 98 & 62.4 & 61 & 60.4 \\
\hline $60-69$ & 52 & 33.1 & 31 & 30.7 \\
\hline $70-79$ & 7 & 4.5 & 7 & 6.9 \\
\hline $80-89$ & 0 & 0.0 & 1 & 1.0 \\
\hline 90 or older & 0 & 0.0 & 1 & 1.0 \\
\hline \multicolumn{5}{|l|}{ Education level } \\
\hline Grade school & 0 & 0.0 & 2 & 1.9 \\
\hline High school degree/equivalent & 11 & 7.0 & 5 & 4.9 \\
\hline Professional/trade school & 9 & 5.7 & 9 & 8.7 \\
\hline Some college & 28 & 17.7 & 16 & 15.5 \\
\hline College degree & 42 & 26.6 & 38 & 36.9 \\
\hline Postgraduate school/degree & 68 & 43.0 & 33 & 32.0 \\
\hline \multicolumn{5}{|l|}{ Annual income $(\$)$} \\
\hline Less than 15,000 & 9 & 5.9 & 3 & 3.1 \\
\hline $15,000-29,000$ & 14 & 9.2 & 11 & 11.3 \\
\hline $30,000-44,000$ & 28 & 18.3 & 15 & 15.5 \\
\hline $45,000-59,000$ & 32 & 20.9 & 23 & 23.7 \\
\hline $60,000-74,000$ & 18 & 11.8 & 11 & 11.3 \\
\hline $75,000-84,000$ & 12 & 7.8 & 11 & 11.3 \\
\hline $85,000-94,000$ & 12 & 7.8 & 7 & 7.2 \\
\hline Greater than 95,000 & 28 & 18.3 & 16 & 16.5 \\
\hline
\end{tabular}

1988; Waliczek et al., 2005; Wood et al., 1969), and the reported instrument reliability is 0.78 (Neugarten et al., 1961).

The LSIA consisted of 20 statements (Table 2). Participants were instructed to read and rate each statement on a 3-point Likert-type scale (Likert, 1967), which included the responses "agree," "disagree," and "I don't know."

SCORING AND DATA ANALYSIS. The LSIA instrument for each respondent was scored using Excel $^{\mathrm{TM}}$ (Version 12.0; Microsoft, Redmond, WA). Respondents received a score on the test instrument ranging from 20 to 60 based on their answers. A positive answer to each survey statement resulted in a score of 3 and an overall score of 60 if positive answers were given for all 20 statements. A negative answer to each survey statement received a score of 1 and resulted in an overall score of 20 if all statements were answered negatively. As a result of organizational structure of individual questions, this coding system required some answers to be reverse-coded, which ensured that the most desirable (positive) answer received the most points. Answers of "I don't know" were considered neutral and received 2 points each. Individual scores were tabulated and entered into the overall data spreadsheet.

The data collected were analyzed using SPSS (Version 11.5 for Windows; SPSS, Chicago, IL). Statistical procedures included descriptive 
Table 2. Analysis of variance comparisons of gardeners' and nongardeners' individual statement response scores from the web-based survey, the Life Satisfaction Index A (LSIA), ${ }^{\mathrm{z}}$ in the study evaluating the influence of gardening on life satisfaction and physical activity of older adults.

\begin{tabular}{|c|c|c|c|c|c|c|c|}
\hline LSIA question $^{z}$ & Category & $\begin{array}{l}\text { Sample } \\
\text { size (no.) }\end{array}$ & $\begin{array}{l}\text { Mean score } \\
(1-3 \text { scale })^{y}\end{array}$ & SD & df & $\mathbf{F}$ & $P$ \\
\hline \multirow{2}{*}{$\begin{array}{l}\text { As I grow, older things seem better than } \\
\text { I thought they would be. }\end{array}$} & Gardeners & 157 & 2.50 & 0.814 & 1 & 0.464 & 0.496 \\
\hline & Nongardeners & 103 & 2.44 & 0.836 & & & \\
\hline \multirow{3}{*}{$\begin{array}{l}\text { I have gotten more of the breaks } \\
\text { in life than most of the people I know. } \\
\text { These are the best years of my life. }\end{array}$} & Gardeners & 158 & 2.53 & 0.746 & 1 & 2.660 & 0.104 \\
\hline & Nongardeners & 103 & 2.40 & 0.844 & & & \\
\hline & Gardeners & 158 & 2.31 & 0.874 & 1 & 2.511 & 0.114 \\
\hline doing a month or a year from now. & Nongardeners & 101 & 2.41 & 0.908 & & & \\
\hline This is the dreariest time of my life. ${ }^{x}$ & Gardeners & 157 & 2.73 & 0.656 & 1 & 0.420 & 0.517 \\
\hline & Nongardeners & 103 & 2.78 & 0.593 & & & \\
\hline \multirow[t]{2}{*}{ I am just as happy as when I was younger. } & Gardeners & 156 & 2.38 & 0.890 & 1 & 0.430 & 0.513 \\
\hline & Nongardeners & 103 & 2.30 & 0.938 & & & \\
\hline My life could be happier than it is now. ${ }^{x}$ & Gardeners & 157 & 1.87 & 0.941 & 1 & 2.492 & 0.116 \\
\hline \multirow{2}{*}{$\begin{array}{l}\text { I expect some interesting and pleasant } \\
\text { things to happen to me in the future. }\end{array}$} & Gardeners & 156 & 2.94 & 0.260 & 1 & 3.587 & 0.059 \\
\hline & Nongardeners & 102 & 2.85 & 0.475 & & & \\
\hline \multirow{2}{*}{$\begin{array}{l}\text { The things I do are as interesting } \\
\text { to me as they ever were. }\end{array}$} & Gardeners & 156 & 2.78 & 0.628 & 1 & 1.867 & 0.173 \\
\hline & Nongardeners & 103 & 2.61 & 0.783 & & & \\
\hline \multirow[t]{2}{*}{ I feel old and somewhat tired. ${ }^{x}$} & Gardeners & 157 & 2.49 & 0.837 & 1 & 8.679 & $0.004^{*}$ \\
\hline & Nongardeners & 103 & 2.19 & 0.961 & & & \\
\hline \multirow[t]{2}{*}{ I feel my age but it does not bother me. } & Gardeners & 156 & 2.32 & 0.937 & 1 & 0.280 & 0.597 \\
\hline & Nongardeners & 103 & 2.30 & 0.938 & & & \\
\hline \multirow{2}{*}{$\begin{array}{l}\text { As I look back on my life, } \\
\text { I feel fairly satisfied. }\end{array}$} & Gardeners & 156 & 2.87 & 0.483 & 1 & 2.512 & 0.114 \\
\hline & Nongardeners & 103 & 2.77 & 0.645 & & & \\
\hline $\begin{array}{l}\text { I would not change my } \\
\text { past even if I could. }\end{array}$ & Gardeners & 155 & 1.92 & 0.967 & 1 & 0.852 & 0.357 \\
\hline \multirow{2}{*}{$\begin{array}{l}\text { Compared with other people, } \\
\text { I get down in the dumps too often. }{ }^{x}\end{array}$} & Gardeners & 157 & 2.80 & 0.536 & 1 & 2.683 & 0.103 \\
\hline & Nongardeners & 102 & 2.66 & 0.711 & & & \\
\hline \multirow{2}{*}{$\begin{array}{l}\text { I have gotten pretty much what } \\
\text { I expected out of life. }\end{array}$} & Gardeners & 158 & 2.61 & 0.720 & 1 & 4.869 & $0.028^{*}$ \\
\hline & Nongardeners & 103 & 2.41 & 0.868 & & & \\
\hline \multirow{2}{*}{$\begin{array}{l}\text { Despite what people say, most } \\
\text { of the people in the world } \\
\text { are overall kindhearted. }\end{array}$} & Gardeners & 154 & 2.64 & 0.721 & 1 & 3.365 & 0.068 \\
\hline & Nongardeners & 101 & 2.44 & 0.805 & & & \\
\hline
\end{tabular}

${ }^{2}$ Neugarten et al., 1961 .

ycores for each statement ranged from 1 to 3 . The numerical value assigned to responses for this question were coded such that a response of "agree" scored 3 points, "I do/ don't know" scored 2 points, and “disagree" scored 1 point for each of the 20 survey statements.

"Indicates that the numerical value assigned to responses for this question was reverse-coded such that a response of "agree" scored 1 point, "I don't know" scored 2 points, and

"disagree" scored 3 points.

* Statistically significant at $P=0.05$.

statistics, frequencies, and analysis of variance to determine differences in LSIA overall scores, to make comparisons of individual question responses included in the LSIA instrument, to determine differences in responses between gardeners and nongardeners on additional questions asked concerning physical activity and overall quality of life and to make comparisons among demographic groups.

\section{Results and discussion}

A total of 298 participant responses were recorded from adults ages 50 years and older on the LSIA perceptions of quality-of-life survey for older adults. The initial sample was reduced to 261 for the final data analysis eliminating duplicate and incomplete surveys. A Cronbach's alpha reliability test indicated the internal consistency of the survey for this study to be 0.83 , which is considered to be an acceptable level (Gall et al., 2006). Analysis of variance tests were used to compare gardeners and 
nongardeners based on demographic information. No significant differences were found between the two groups on any of the demographic variables, including age, gender, ethnicity, income, and education indicating that gardeners and nongardeners were similar in terms of demographics outside of the variable of interest of participation in gardening.

COMPARISON OF GARDENER AND NONGARDENER LifE SATISFACTION INVENTORY A sCORES. An unbalanced analysis of variance was used to compare gardeners' and nongardeners' sample sizes. Statistically significant results were reported in comparisons of the overall LSIA scores. Gardeners had higher mean scores (36.06) compared with nongardeners $(34.40)$ on overall LSIA scores $(P=0.01)$ (Table $3)$. This result is similar to a study done by Waliczek et al. (2005) that reported significant differences of LSIA scores with gardeners of all ages reporting more positive scores compared with nongardeners of all ages.

These differences in scores indicated that gardeners had more positive perceptions regarding their life satisfaction when compared with their nongardening counterparts. Boyer et al.'s (2002) study supports this finding by reporting that statistically significant improvements were found in quality-of-life categories, including perceptions of physical and social activity, self-esteem, and nutrition of those who were actively involved in a Master Gardener program. Blair et al. (1991) also reported that gardeners responded with more positive quality-of-life scores when compared with nongardeners, leading to the conclusion that "those who are involved in gardening find life more satisfying and feel they have more responses to account for unequal

positive things happening in their lives than those who are not."

Individual Life SATISFAction INVENTORY A STATEMENT COMPARIsons. After finding statistically significant differences between gardeners and nongardeners in overall scores regarding perceptions of life satisfaction, individual statements were analyzed to discover any differences that may have occurred in responses within the different categories on the LSIA between the two groups. Statistically significant differences were found on $20 \%$, or four of the 20 life satisfaction questions. Each of these four statements was answered more positively by respondents who identified themselves as gardeners. Statements did not occur in any one category but in a variety of life satisfaction categories contained within the instrument (Table 2).

INDIVIDUAL STATEMENT COMPARIsons. Related to "optimism," more than $84 \%$ of gardeners agreed with the statement, "I have made plans for things I'll be doing a month or a year from now" compared with only $68 \%$ of nongardeners $(P=0.000)$ (Table $2)$. Differences were observed in that $28.2 \%$ of nongardeners disagreed to the statement, whereas only $11.4 \%$ of gardeners disagreed, showing optimism by those who garden. These findings supported results reported by Waliczek et al.'s (2005) in which $67 \%$ of gardeners of all ages agreed with the same statement, whereas only $52 \%$ of nongardeners agreed. It has been suggested that horticultural therapy has promoted positive attitudes in participants in part as a result of offering participants a sense of accomplishment and a form of control over a small part of his or her life along with hope for what is yet to come (Shapiro and Kaplan, 1997). Gardening is an ongoing recreation

Table 3. Analysis of variance comparisons of gardeners' and nongardeners' overall response scores on the Life Satisfaction Index A (LSIA) ${ }^{\mathrm{z}}$ in the study evaluating the influence of gardening on life satisfaction and physical activity of older adults.

\begin{tabular}{lcccccc}
\hline Category & $\begin{array}{c}\text { Sample } \\
\text { size (no.) }\end{array}$ & $\begin{array}{c}\text { Mean score } \\
(\mathbf{2 0 - 6 0} \text { scale) }\end{array}$ & SD & df & F & $\boldsymbol{P}$ \\
\hline Gardeners & 158 & 36.06 & 4.698 & 1 & 6.710 & $0.010^{*}$ \\
Nongardeners & 103 & 34.40 & 5.565 & & & \\
\hline
\end{tabular}

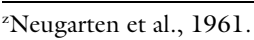

y Scores ranged from 20 to 60 with 20 being the lowest possible score and 60 being the highest possible score.

These scores are based on a rating in which $1=$ a negative response and $3=$ a positive response to each of the 20 survey statements.

* Statistically significant at $P=0.05$ that is available 12 months a year whether planning, planting, picking, or preserving allowing a gardener to maintain an active body and mind while preparing for the next step. According to Lewis (1996), gardening requires patience and planning, a vision for the future as well as a belief in what some still see as a miracle in the germination of seeds.

Statistical significance was also found in the "zest for life" statement, "most of the things I do are boring and monotonous." Over $96 \%$ of gardeners disagreed with this statement, whereas $85.3 \%$ of nongardeners disagreed $(P=0.002)$ (Table 2$)$. These findings supported a quality-of-life study by Waliczek et al. (2005) that also found a larger percentage of gardeners of all ages disagreeing with this statement. Gardening experiences appear to add interest in gardeners' day-to-day activities.

Additional statistically significant differences between gardeners and nongardeners were noted in the "energy level" statement, "I feel old and somewhat tired" $(P=0.004)$ (Table $2)$. Gardeners disagreed with the statement at a rate of $70.9 \%$, whereas $57.3 \%$ of nongardeners disagreed with the statement. Gardening has been reported as one of the most popular home-based leisure activities in the United States (Ashton-Shaeffer and Constant, 2005) and the second most common leisure activity, after walking, of adults older than age 65 years (Yusuf et al., 1996). Although adults garden for many reasons, physical health and exercise as well as mental health are often cited (Ashton-Shaeffer and Constant, 2005; Blair et al., 1991). Gardening appears to have had a positive effect on those whom were participating from this study.

The statement, "I've gotten pretty much what I expected out of life," which related to the "congruence between desired and achieved goals" category on the LSIA, also demonstrated statistical significance when gardeners agreed $74.3 \%$ of the time compared with $66 \%$ of nongardeners answering in the same way $(P=$ 0.028) (Table 2). Gardens offer a variety of pleasures to growers, including exercise, recreation, creativity, friendship, and contact with nature (Ashton-Shaeffer and Constant, 2005; Blair et al., 1991). These reasons 
for gardening offer a sense of accomplishment when the cycle of life is so visible and rapidly completed during growing seasons or years in the garden (Clayton, 2007; Kaplan, 1973; Lewis, 1996).

Comparisons of gardeners' AND NONGARDENERS' LEVELS OF PHYSICAL ACTIVITY. Statistically significant differences between gardeners and nongardeners were noted on responses to how participants rated their normal daily physical activity $(P=0.000)$ (Table 4). Respondents answered the multiple-choice question asking, "In a usual day, are you physically 'very active,' 'moderately active,' or 'quite inactive'?" Although the answers were not quantified, gardeners and nongardeners selected the answer that they felt most reflected their personal lifestyle. Over three times as many nongardeners (14.71\%) compared with gardeners $(4.43 \%)$ considered themselves to be "quite inactive." In turn, $38 \%$ of gardeners considered themselves to be very active compared with only $19.6 \%$ of nongardeners. These data are similar to Waliczek et al.'s (2005) study in which almost twice as many nongardeners considered themselves to be quite inactive when compared with gardeners, and $25 \%$ of gardeners considered themselves to be "quite active" compared with only $18.5 \%$ of nongardeners. According to the Compendium of Physical Activities, gardening activities are classified as light to moderate physical exercise and are a good exercise option for a range of age and ability levels (Ainsworth et al., 2000; Schlettwein-Gsell, 1992) because the exercise can be linked to purpose as well as enjoyment (Catlin, 1997). Light to moderate physical activity demonstrates benefits for cardiovascular and all-cause mortality and is linked to increased consumption of fruit and vegetables in older adults (Mummery et al., 2007; Sahyoun et al., 2005; Wannamethee and Sharper, 2001).

Comparisons of gardeners' AND NONGARDENERS' REPORTS OF OVERALL HEALTH. Better physical and nutritional habits could be inferred as a result of the statistical differences reported by gardeners compared with nongardeners when they were asked to rate their overall health on a 5 -point Likert scale with answers ranging from "poor" to "excellent" $(P=0.005)$ (Table 5). More gardeners rated their health as "very good" $(39.1 \%)$ or "excellent" (36.5\%) when compared with nongardeners (36.9\% and $26.2 \%)$. Gardeners are reported to eat more fruit and vegetables because of exposure (Devine et al., 1999), and this, in conjunction with higher physical activity, results in healthier lifestyles and increased quality of life (Blanchard et al., 2004; CDC, 2007; Lancaster, 2004).

\section{Conclusions}

This study provides evidence that gardening can be used as an effective tool with adults aged 50

Table 4. Analysis of variance comparisons of gardeners' and nongardeners' responses to the question, “In your usual day, are you physically 'quite inactive,' 'moderately active,' or 'very active'?” in the study evaluating the effects of gardening on life satisfaction and physical activity of older adults.

\begin{tabular}{lcccccc}
\hline Category & $\begin{array}{c}\text { Sample } \\
\text { size (no.) }\end{array}$ & $\begin{array}{c}\text { Mean score } \\
(\mathbf{1}-3 \text { scale })^{\mathrm{z}}\end{array}$ & SD & df & F & $\boldsymbol{P}$ \\
\hline Gardeners & 158 & 2.34 & 0.560 & 1 & 15.623 & $0.000^{*}$ \\
Nongardeners & 102 & 2.05 & 0.587 & & & \\
\hline
\end{tabular}

${ }^{\mathrm{z}} 1=$ quite inactive, $2=$ moderately active, $3=$ very active.

* Statistically significant at $P=0.05$.

Table 5. Analysis of variance comparisons of gardeners' and nongardeners' responses to the statement, "Rate your overall health," in the study evaluating the effects of gardening on life satisfaction and physical activity of older adults.

\begin{tabular}{lcccccc}
\hline Category & $\begin{array}{c}\text { Sample size } \\
\text { (no.) }\end{array}$ & $\begin{array}{c}\text { Mean score } \\
(\mathbf{1}-\mathbf{5} \text { scale) }\end{array}$ & SD & df & F & $\boldsymbol{P}$ \\
\hline Gardeners & 156 & 4.09 & 0.838 & 1 & 7.941 & $0.005^{*}$ \\
Nongardeners & 103 & 3.77 & 0.992 & & & \\
\hline
\end{tabular}

${ }^{\mathrm{z}} 1=$ poor, $2=$ fair, $3=$ good, $4=$ very good, $5=$ excellent

* Statistically significant at $P=0.05$.

years or older to increase life satisfaction while also increasing physical activity levels in a population that may otherwise begin to lose mobility and/or exercise less. Additionally, past studies have found that gardening programs can fill social/leisure gaps in populations while offering nutritional information and availability of fresh produce to improve health (Koch et al., 2006; Waliczek et al., 1996). In a time when older adults are living longer and enjoying more free time, gardening offers the opportunity to fulfill needs created by changing lifestyles. Gardening provides participants with opportunities to reconnect with themselves through nature and a healthy activity to enhance their quality of life.

\section{Literature cited}

AARP. 2010. AARP. 21 May 2010. <http://www.aarp.org/>.

Adams, D.L. 1969. Analysis of a life satisfaction index. J. Gerontol. 24:470-474.

Ainsworth, B.E., W.L. Haskell, M.C. Whitt, M.L. Irwin, A.M. Swartz, S.J. Strath, W.L. O'Brien, D.R. Bassett, Jr., K.H. Schmitz, P.O. Emplanincourt, D.R. Jacobs, Jr., and A.S. Leon. 2000. Compendium of physical activities: An update of activity codes and MET intensities. Med. Sci. Sports Exerc. 32:S498-S516.

Andersen, R.E., S. Franckowiak, C. Christmas, J. Walston, and C. Crespo. 2001. Obesity and reports of no leisure time activity among older Americans: Results from the Third National Health and Nutrition Examination Survey. Educ. Gerontol. 27:297-306.

Arias, E. 2007. United States life tables, 2004. Natl. Vital Stat. Rep. 56:1-6.

Arterburn, D.E., P.K. Crane, and S.D. Sullivan. 2004. The coming epidemic of obesity in elderly Americans. J. Amer. Geriatr. Soc. 52:1907-1912.

Ashton-Shaeffer, C. and A. Constant. 2005. Why do older adults garden? Act. Adaptation Aging 30:1-18.

Bertera, E.M. 2003. Physical activity and social network contacts in community dwelling older adults. Act. Adaptation Aging 27:113-127.

Blair, D., C.C. Giesecke, and S. Sherman. 1991. A dietary, social, and economic evaluation of the Philadelphia urban gardening project. J. Nutr. Educ. 23:161-167.

Blanchard, C.M., K.D. Stein, F. Baker, M.F. Dent, M.M. Denniston, K.S. Courneya, and E. Nehl. 2004. Association 
between current lifestyle behaviors and health-related quality of life in breast, $\mathrm{co}^{-}$ lorectal and prostate cancer survivors. Psychol. Health 19:1-13.

Boyer, R., T.M. Waliczek, and J.M. Zajicek. 2002. The master gardener program: Do benefits of the program go beyond improving the horticultural knowledge of the participants? HortTechnology 12:432436.

Catlin, P. 1997. Developmental disabilities and horticultural therapy practice, p. 131-156. In: S.P. Simson and M.C. Straus (eds.). Horticulture as therapy: Principles and practice. Food Products Press, New York, NY.

Centers for Disease Control and Prevention. 2007. Improving the health of older Americans: A CDC priority. Chronic Dis. Notes Rpt. 18:1-7.

Clayton, S. 2007. Domesticated nature: Motivations for gardening and perceptions of environmental impact. J. Environ. Psychol. 27:215-224.

Devine, C.M., W.S. Wolfe, E.A. Frongillo, and C.A. Bisogni. 1999. Life-course events and experiences: Association with fruit and vegetable consumption in 3 ethnic groups. J. Amer. Dietetic Assn. 99:309-314.

Gall, M.D., W.R. Borg, and J.P. Gall. 2006. Educational research: An introduction, 8th Ed. Allyn and Bacon, White Plains, NY.

Infantino, M. 2005. Gardening: A strategy for health promotion in older women. J. N. Y. State Nurses Assoc. 35:10-17.

Kaplan, R. 1973. Some psychological benefits of gardening. Environ. Behav. 5: $145-162$.

Koch, S., T.M. Waliczek, and J.M. Zajicek. 2006. The effect of a summer garden program on the nutritional knowledge, attitudes, and behaviors of children. HortTechnology 16:620-625.
Lancaster, K.J. 2004. Characteristics influencing daily consumption of fruits and vegetables and low-fat dairy products in older adults with hypertension. J. Nutr. Elder. 23:21-33.

Lewis, C. 1996. Green nature/human nature. University of Illinois Press, Chicago, IL.

Likert, R. 1967. The method of constructing an attitude scale, p. 90-95. In: M. Fishbein (ed.). Readings in attitude theory and measurement. Wiley, New York, NY.

Miller, R.K. and K.D. Washington. 2007. Baby boomer consumers, p. 68-76. In: Consumer behavior 2007. Richard K. Miller \& Assoc., Loganville, GA.

Mummery, W.K., G. Kolt, G. Schofield, and G. McLean. 2007. Associations between physical activity and other lifestyle behaviors in older New Zealanders. J. Phys. Act. Health 4:411-422.

Neugarten, B.L., R.J. Havighurst, and S.S. Tobin. 1961. The measurement of life satisfaction. J. Gerontol. 16:134-143.

Rossner, S. 2001. Obesity in the elderly-A future matter of concern? Obes. Rev. 2: 183-188.

Sahyoun, N.R., X.L. Zhang, and M.K. Serdula. 2005. Barriers to the consumption of fruits and vegetables among older adults. J. Nutr. Elder. 24:5-21.

Schlettwein-Gsell, D. 1992. Nutrition and the quality of life: A measure for the outcome of nutritional intervention? Amer. J. Clin. Nutr. 55:1263S-1266S.

Sexton, D.L. and B.H. Munro. 1985. Impact of a husband's chronic illness (COPD) on the spouse's life. Res. Nurs. Health 8:83-90.

Sexton, D.L. and B.H. Munro. 1988 Living with a chronic illness: The experience of women with chronic obstructive pulmonary disease (COPD). West. J. Nurs. Res. 10:26-44.
Shapiro, B.A. and M.J. Kaplan. 1997. Mental illness and horticultural therapy practice, p. 157-197. In: S.P. Simson and M.C. Straus (eds.). Horticulture as therapy: Principles and practice. Food Products Press, New York, NY.

Sommerfeld, A.J., A.L. McFarland, T.M. Waliczek, and J.M. Zajicek. 2010. Growing minds: Evaluating the relationship between gardening and fruit and vegetable consumption in older adults. HortTechnology 20:711-717.

U.S. Department of Health and Human Services. 2007. A profile of older Americans: 2005. U.S. Dept. Health Human Services, Washington, DC.

Waliczek, T.M., R.H. Mattson, and J.M. Zajicek. 1996. Psychological benefits of community gardening. J. Environ. Hort. 14:204-209.

Waliczek, T.M., J.M. Zajicek, and R.D. Lineberger. 2005. The influence of gardening activities on consumer perceptions of life satisfaction. HortScience 40:13601365 .

Wannamethee, S.G. and A.G. Sharper. 2001. Physical activity in the prevention of cardiovascular disease-An epidemiological perspective. Sports Med. 31:101114.

Willcox, R. and R.H. Mattson. 1979. Horticultural therapy maintains life-satisfaction of geriatrics. Great Plains J. Hort. Therapy $1: 8-12$.

Wood, V., M.L. Wylie, and B. Sheafor. 1969. An analysis of a short self-report measure of life satisfaction. Correlation with rater judgments. J. Gerontol. 24: 465-469.

Yusuf, H.R., J.B. Croft, W.H. Giles, R.F. Anda, M.L. Casper, C.J. Caspersen, and D.A. Jones. 1996. Leisure-time physical activity among older adults. Arch. Intern. Med. 156:1321-1326. 